\title{
O ARCO OCUPACIONAL SAÚDE NAS POLÍTICAS DE EDUCAÇÃO PROFISSIONAL
}

\author{
THE HEALTH OCCUPATIONAL ARCH IN THE PROFESSIONAL EDUCATION POLICIES
}

\author{
Neise Deluiz ${ }^{1}$ \\ Bianca Ribeiro Veloso ${ }^{2}$
}

Resumo Este artigo tem como objetivo analisar as expectativas dos alunos em relação aos cursos de qualificação profissional do arco ocupacional saúde do Projovem Trabalhador no Rio de Janeiro, as concepções e estratégias pedagógicas utilizadas nos cursos e as mudanças ocorridas em sua situação social nas dimensões educacional, econômica, psicossocial e político-social. Trata-se de pesquisa qualitativa que utilizou grupos focais e entrevistas com os 58 alunos dos cursos. Na dimensão educacional, a qualificação profissional recebida foi insuficiente e não preparou os alunos para enfrentar os desafios do mercado de trabalho. A maioria continua buscando cursos como forma de aumentar as chances de trabalho. Na dimensão econômica, a maior parte dos jovens permaneceu desempregada, e na dimensão psicossocial observou-se referência às questões relativas à subjetividade, à autoestima, melhor comunicação e sociabilidade. Quanto à dimensão político-social, o maior ganho dos alunos foi na compreensão dos seus direitos como cidadãos, mas esta não os levou a atuar nos espaços da sociedade civil, como sindicatos e movimentos sociais. Conclui-se que as percepções dos alunos e os sentidos que atribuem ao Programa refletem as contradições da política, indicando que os jovens não são somente receptores passivos, mas sujeitos de direitos e protagonistas que reivindicam uma formação que atenda aos seus interesses.

Palavras-chave educação profissional; Projovem trabalhador; juventude.
Abstract This article aims to analyze the students' expectations with regard to the vocational training courses provided under the "Projovem Trabalhador" occupational health arch, in Rio de Janeiro, the educational concepts and strategies used in the courses, and the changes that took place in their social situation in the educational, economic, psychosocial and socio-political dimensions. This is a qualitative study that used focus groups and interviews with 58 students of the courses. In the educational dimension, vocational skills received were insufficient and did not prepare students to face the challenges of the labor market. Most continue pursuing courses in order to increase their chances of employment. In the economic dimension, most of the young people remained unemployed, while in psychosocial dimension there was reference to the issues of subjectivity, self-esteem, and improved communications and sociability. Insofar as the socio-political dimension is concerned, the students' biggest gain was in understanding their rights as citizens, but this did not lead them to act in the spaces of society, such as trade unions and social movements. It is concluded that the students' perceptions and the meanings that they attribute to the Program reflect the contradictions of the policy, indicating that young people are not mere passive recipients, rather subjects of rights and protagonists that demand an education that meets their interests.

Keywords professional education; Projovem Trabalhador; youth. 
As políticas sociais implementadas sob a orientação dos organismos internacionais na América Latina a partir dos anos 1990 assumem as seguintes características: são focais e temporárias e tendem a perder seu caráter universal e a se tornar um mero paliativo reservado aos excluídos do mercado; estão direcionadas para os extremamente pobres - incapazes de suportar os custos dos ajustes e reformas ocorridos nestes países -, e destinam-se a garantir um mínimo de serviços de primeira necessidade e de infraestrutura social. São políticas de assistência-benfeitoria e de privatização, nas quais as organizações não governamentais (ONGs) transformam-se em instâncias intermediárias fundamentais, tanto na identificação dos grupos mais desfavorecidos quanto na distribuição de ajudas, recorrendo à participação popular, com apelo à caridade e ao apoio comunitário, em oposição à lógica dos direitos sociais universais. Por fim, caracterizam-se pela descentralização objetivando maior eficiência e racionalização dos gastos (Salama e Valier, 1997).

Nesta última década permanecem os pressupostos destas políticas, pois a presença de significativa parcela da sociedade brasileira ainda na faixa da pobreza tem obrigado o Estado a criar e manter programas compensatórios para minimizar os impactos do ritmo do crescimento econômico e evitar uma possível desagregação do tecido social. Segundo Castel (1998, p.498), “todo Estado moderno é mais ou menos obrigado a 'fazer social' para mitigar algumas disfunções gritantes, [e] assegurar um mínimo de coesão entre os grupos sociais".

De acordo com Wanderley (2004), apesar de ter ocorrido progresso no crescimento econômico e em certas conquistas sociais, as desigualdades e injustiças na estrutura social vão se avolumar devido às relações assimétricas de dominação, subordinação na produção, no poder político, na estrutura de classe e na estratificação social. Para Silva (2010), a análise do quadro social brasileiro evidencia, ainda, significativa persistência da pobreza e da desigualdade social, com diminuição nesses índices a partir de medidas adotadas desde a Constituição brasileira de 1988. Nos últimos anos tem havido a possibilidade de superação da indigência, embora a pobreza, mesmo que diminuindo de modo mais significativo do que a desigualdade social, pareça vir sendo apenas administrada e controlada. Cattani (2007) aponta que, nos últimos anos, tem sido observada a redução do número de famílias situadas abaixo da linha da pobreza, entretanto, a desigualdade socioeconômica não é medida por uma arbitrária linha de rendimentos abaixo da qual se situam os pobres, e sim pelas distâncias entre as posições relativas ocupadas pelos diversos segmentos da sociedade.

As políticas públicas voltadas para educação profissional inicial e continuada de jovens de baixa renda inserem-se neste contexto de desigualdade, pobreza e exclusão, e têm por objetivo dar respostas às questões sociais postas pelo quadro de extrema vulnerabilidade deste segmento da popula- 
ção. Estas questões tenderam a se agravar com o contínuo estreitamento do mercado de trabalho, em face do aprofundamento do processo de reestruturação do setor produtivo e da redução dos postos de trabalho, por um lado, e à desaceleração da economia decorrente da crise internacional que eclode em 2008, por outro.

Diante do excedente de mão-de-obra pouco escolarizada e qualificada e sem experiência prévia e do aumento de exigências de ampliação do conhecimento dos trabalhadores, os jovens dos setores empobrecidos têm como desafios a inserção e a permanência no mundo do trabalho. Além do ônus do desemprego, enfrentam a precarização do trabalho, constatada nos baixos salários, extensas jornadas de trabalho, informalidade das relações de trabalho e na ausência de mecanismos de proteção social e trabalhista.

Entre as políticas públicas do governo federal sobre formação inicial e continuada de jovens trabalhadores, privilegiamos como foco de estudo o Projovem Trabalhador no município do Rio de Janeiro. Uma de suas linhas de ação - Juventude Cidadã -, promove ações de qualificação profissional em uma rede de ONGs em parceria com o Ministério do Trabalho e Emprego (MTE) e a Secretaria Municipal de Trabalho e Emprego (SMTE).

O presente trabalho tem como objetivo analisar, com base na perspectiva dos alunos do arco ocupacional saúde 3 do Projovem Trabalhador no Rio de Janeiro, suas expectativas em relação aos cursos de qualificação profissional, as concepções e estratégias pedagógicas utilizadas nos cursos e as mudanças ocorridas em sua situação social nas dimensões educacional (qualificação profissional e ampliação da escolaridade), econômica (trabalho/renda), psicossocial e político-social (exercício da cidadania).

\section{Juventude e trabalho diante das reformas políticas, econômicas e sociais gestadas no país}

A temática da juventude é suscetível de polêmicas e controvérsias e entre elas a indagação se a juventude poderia ser considerada uma categoria de análise. De acordo com Groppo (2000, p. 7), “ao ser definida como categoria social a juventude torna-se, ao mesmo tempo, uma representação sociocultural e uma situação social". Segundo o autor, as definições de juventude passeiam por dois critérios principais, que nunca se conciliam realmente: o critério etário (herdeiro das primeiras definições psicofisiológicas) e o critério sociocultural. Assim, além do elemento cronológico, o que define a juventude é a forma como o jovem se insere socialmente e de que forma a cultura é influenciada por ele e o influencia.

A caracterização da juventude como criação sociocultural é um elemento substancial, porque no caso dos jovens contemporâneos é necessário 
analisar sua relação com as mudanças aceleradas que afetam não só o mundo do trabalho, mas a vida social como um todo.

A despeito do uso comum do termo 'juventude', o conceito de juventude não é unívoco, por razões tanto históricas quanto sociais e culturais. Não se pode falar de uma 'juventude brasileira', mas sim de 'juventudes' (Corrochano et al., 2008), pois os jovens se diferenciam de acordo com suas condições econômica e social, de gênero, etnia e local de origem, entre outras. Todas essas especificidades criam condições peculiares a cada jovem em relação à escolarização, à exposição de riscos e à luta pela entrada no mercado de trabalho, que não podem ser desconsideradas.

Segundo Groppo (2000):

a multiplicidade das juventudes não se funda num vazio social ou num nada cultural, não emerge de uma realidade meramente diversa, ininteligível e esmaecida. Tem como base experiências socioculturais anteriores, paralelas ou posteriores, que criaram e recriaram as faixas etárias e institucionalizaram o curso da vida individual - projetos e ações que fazem parte do processo civilizador da modernidade (Groppo, 2000, p. 19).

Entretanto, os jovens têm características que lhes são próprias e, desta forma, "teimam em ser uma unidade do diverso econômico, cultural, étnico, de gênero, de religião, etc." (Frigotto, 2004, p. 181). Têm em comum o enfrentamento das condições adversas de um desenvolvimento desigual e combinado do país, que se traduz na desigualdade econômica e social, no desemprego e na precarização do trabalho, ainda que os enfrentem de forma diferenciada, de acordo com sua classe social, nível de escolarização, origem étnica e cultural.

Entre as várias concepções de juventude presentes na sociedade assinalam-se as que a compreendem como um período preparatório para o mundo adulto, como um espaço de tempo entre a infância e a idade adulta. Sob esta ótica, a proposta educacional representa apenas um complemento à oferta educativa, com a organização de atividades dirigidas ao uso do tempo livre, ao voluntariado, ao lazer e esporte e, em decorrência, ela não é vista como propulsora de ações que possam vir a contribuir para a formação integral do jovem.

O segundo tipo de concepção relaciona a juventude a uma etapa problemática, onde o jovem é considerado a partir da manifestação de alguma deficiência em seu desenvolvimento ou dos problemas que ocasiona e que ameaçam a ordem social. As políticas decorrentes da apropriação dessa concepção são sempre compensatórias, com foco nos segmentos que apresentam as características de risco, vulnerabilidade ou transgressão. Em uma terceira concepção de juventude, o jovem é ator estratégico de desenvolvimento, 
objetivando a formação do capital humano e social para possibilitar o enfrentamento dos problemas de exclusão social que o ameaçam e que dificultam a modernização das sociedades diante das exigências postas pelos novos padrões mundiais (Abramo, 2005).

Finalmente, uma quarta concepção considera a juventude como etapa singular do desenvolvimento pessoal e social, “(...) e os jovens passam a ser considerados como sujeitos de direitos e deixam de ser definidos por suas incompletudes ou desvios" (Abramo, 2005, p. 22). Essa concepção se desenvolve, em alguns países, após os anos de 1990, possibilitando políticas articuladas intersetorialmente, centradas na noção de cidadania, onde os jovens são considerados como sujeitos integrais.

Em relação ao mundo do trabalho, a realidade dos jovens pesquisados por Dayrell (2003) indica que para eles a juventude é um momento de dificuldades concretas de sobrevivência e de tensões com o trabalho e a família. O trabalho assume centralidade para os jovens e se converte em uma obrigação necessária para a sobrevivência nesta sociedade assalariada, que cria uma massa que vive à margem, e que transforma esse momento transitório em momento permanente.

Dayrell (2003) conclui que o mundo do trabalho pouco contribuiu no processo de humanização dos jovens, não lhes dando a oportunidade de ampliar suas potencialidades. Tornou-se um espaço impermeável às suas necessidades que os impediu de se construírem como sujeitos integrais. Portanto, os espaços de trabalho e educação pouco podem fazer se não estiverem ligados a uma rede de sustentação mais ampla, com políticas públicas que garantam espaços e tempos para que os jovens possam se colocar de fato como sujeitos e cidadãos, com direito a viver plenamente a juventude. Dentre estes direitos de cidadania estão o direito ao trabalho e à educação de qualidade.

O direito ao trabalho decente consta da Carta das Nações Unidas, contudo o desemprego e a precarização do trabalho dos jovens vêm se configurando entre os mais graves problemas da atualidade. A dramática situação da falta e da baixa qualidade dos postos de trabalho e as dificuldades de acesso à rede de proteção social, decorrentes das reformas políticas, econômicas e sociais gestadas no país nas últimas décadas, acabam por transformar a fase da juventude em uma etapa de incerteza.

O Anuário do Sistema Público de Emprego, Trabalho e Renda 2010/2011 do Departamento Intersindical de Estatística e Estudos Socioeconômicos (DIEESE), em parceria com o Ministério do Trabalho e Emprego (MTE) (DIEESE, 2011), baseado em dados de 2009, aponta que no Brasil a população de 16 a 29 anos totalizava aproximadamente 46.340.000, sendo $33.880 .000(73,11 \%)$ o quantitativo da população economicamente ativa (PEA) e $12.461 .000(26,89 \%)$ da população não economicamente ativa (PNEA). 
Do quantitativo da PEA, 28.954 .000 (85,5\%) estavam ocupados enquanto $4.926 .000(14,5 \%)$ desocupados.

Do total de jovens de 16 a 29 anos ocupados, 45,3\% eram empregados com carteira assinada, 24,8\% eram empregados sem carteira, 10,9\% trabalhavam por conta própria, $5 \%$ eram trabalhadores domésticos sem carteira e $1,1 \%$ com carteira, 3,6\% eram militares e estatutários, 1,6\% eram empregadores, 2,2\% trabalhavam para o autoconsumo e 5,5\% não eram remunerados. A soma dos percentuais de jovens trabalhadores empregados sem carteira, trabalhadores domésticos sem carteira, trabalhadores para o autoconsumo e não remunerados $(37,4 \%)$ revela a face do trabalho precarizado, sem direitos trabalhistas e previdenciários em que os jovens se inserem.

Segundo o Anuário do DIEESE (2011), no Estado do Rio de Janeiro a população de 16 a 29 anos era de 3.410 .000 em 2009. Desse total, a PEA totalizava $2.332 .000(68,37 \%)$ enquanto a PNEA em $1.079 .000(31,63 \%)$. Do quantitativo da PEA no Rio de Janeiro, 1.941 .000 (83,2\%) estavam ocupados enquanto $391.000(16,8 \%)$ desocupados. A proporção de jovens assalariados sem carteira sobre o total de jovens de 16 a 29 anos assalariados era de $35,6 \%$.

Os dados da relação trabalho e educação constantes no Anuário do DIEESE (2011) revelam que a média de anos de estudo da população jovem de 16 a 24 anos no Brasil era, em 2004, de 8,2 anos para a população total e 9,3 para a PEA. Em 2009 a média de anos de estudo subiu para 9,2 anos para a população total e 9,5 para a PEA. No Estado do Rio de Janeiro a média da população total em 2004 era de 9,0 e a da PEA 9,3, maior que a média nacional. O mesmo ocorre em 2009, em que a média da população total é de 9,6 anos de estudo e da PEA 10 anos de estudo. Em 2009 o quantitativo de jovens que só trabalham e/ou procuram trabalho no Brasil foi estimado em $55,2 \%$, ou seja, mais da metade da população de 16 a 29 anos. Destes, $17,9 \%$ estudam e trabalham e/ou procuram trabalho, $13,5 \%$ da população de 16 a 29 anos só estudam, e 13,4\% estão em outras situações não especificadas no Anuário do DIEESE (2011). Estes dados indicam a necessidade de se definir como prioridade política o combate ao trabalho precoce no mercado formal ou informal e, ao mesmo tempo, apontar a relevância da política de universalização efetiva do ensino nos níveis fundamental e médio.

De acordo com os dados do DIEESE (2011), a variação de rendimento mensal é proporcional à escolaridade do jovem. Quanto menor a escolaridade, menor é o rendimento mensal. Do quantitativo de jovens ocupados de 16 a 29 anos e analfabetos, a maioria $(80,8 \%)$ recebe até um salário mínimo, enquanto $1,8 \%$ recebem mais de dois salários mínimos. Do total de jovens com fundamental completo, $52 \%$ recebem até um salário mínimo por mês. Do total de jovens com ensino médio completo, 49,9\% recebem mais de 1 a 2 salários mínimos por mês. Jovens com ensino superior completo nesta 
faixa etária estão em sua maioria concentrados na categoria 'mais de dois salários mínimos por mês' com $68,9 \%$ do total de jovens ocupados.

O retrato dos jovens de 16 a 29 anos no Brasil em 2009, conforme dados apresentados pelo DIEESE (2011), mostra a insuficiência de políticas públicas que possam encaminhar soluções estruturais para as questões da juventude na sua relação com trabalho e com a escolaridade. Dos dados colhidos em 2009 e apresentados em 2011 pelo Dieese em parceria com o MTE, pode-se concluir que na sociedade brasileira os jovens de 16 a 29 anos estão mais sujeitos ao desemprego e ao trabalho precário e deixam a escola prematuramente para buscar a inserção no mercado de trabalho. A situação das jovens mulheres é mais grave, pois, além de enfrentar a discriminação no mercado de trabalho, a ela é atribuída a carga dos afazeres domésticos e do cuidado com os filhos.

São complexas as causas do crescimento do desemprego juvenil. Para Pochmann (2000), as causas estão na combinação de alguns fatores: o crescimento demográfico dessa faixa etária, que gera um maior excedente de mão de obra, aliado à entrada maciça de mulheres disputando uma vaga no mercado de trabalho; o reduzido crescimento econômico - que não facilita a criação de uma significativa quantidade de novos postos de trabalho; e a falta de políticas públicas dirigidas a essa população.

\section{Políticas de qualificação profissional e juventude}

As mudanças tecnológicas e a reconfiguração dos mercados internacionais ocorridas nas últimas décadas aprofundaram o processo de mundialização do capital, impondo ajustes nos níveis macro e microeconômicos nos países centrais e periféricos, com consequentes impactos sociais e políticos. A reestruturação das empresas para enfrentar o aumento da competição no mercado nacional e global inaugurou um novo tempo de instabilidades (Antunes, 2005; Harvey, 1992). O mundo do trabalho modificou-se rapidamente, colocando em xeque o consenso protetor do Estado de Bem-Estar social, que foi substituído pelas políticas focalizadas do 'Estado mínimo'.

No Brasil, a reestruturação das atividades produtivas e sua articulação à rede do capital transnacionalizado (Hobsbawm, 1995) trouxeram novas configurações do trabalho, caracterizadas pela flexibilidade decorrente da desregulamentação dos mercados e da força de trabalho, em um contexto de não-emprego e da crise da sociedade salarial (Castel, 1998). Em uma situação social historicamente marcada pela precarização e informalização das relações de trabalho, aprofundam-se as desigualdades de gênero, de raça e de geração.

Associado às mudanças macro e microeconômicas observa-se o processo de reorganização do Estado em face das necessidades criadas pela nova 
etapa do processo de acumulação capitalista. Novas relações entre Estado e sociedade civil são definidas e esta última passa a ter um papel fundamental na implementação das políticas públicas.

A compreensão da dinâmica da sociedade civil brasileira não pode ser feita de forma desvinculada das reformas do aparelho do Estado na década de 1990. Desta forma, a discussão das novas relações Estado-sociedade civil permite compreender as mudanças ocorridas a partir das políticas neoliberais, como a constituição da esfera pública não-estatal ou 'terceiro setor', a desresponsabilização do Estado com os direitos sociais - transformando-os em serviços e em mercadorias a serem consumidos -, o enfraquecimento do público e a mudança no conceito de cidadania, entre outras (Montaño, 2002).

A partir da década de 1990, as mudanças nos planos econômico e político-ideológico ocorridas no país transformaram as políticas sociais. No plano econômico, a implementação das políticas é determinada pela crise econômica e pelos impactos negativos no mercado de trabalho, ocasionados pelo processo de reestruturação produtiva em curso no país. As várias demandas geradas pelo desemprego são endereçadas a programas sociais que não estão preparados para atendê-las. As consequências traduzem-se na perda de eficácia dos programas, no enfraquecimento do sistema de direitos e na redução da complementaridade entre programas e áreas. No plano político-ideológico, esses novos condicionamentos do sistema de proteção social dizem respeito tanto à redução das funções sociais do Estado, quanto ao estabelecimento de uma nova relação Estado/mercado, fruto da hegemonia do ideário neoliberal nos planos governamentais e das diretrizes impostas pelos organismos internacionais de financiamento.

Deste modo, a reforma empreendida no âmbito do Estado e as políticas de ajuste macroeconômico, nos anos 1990, restringiram o gasto público em atividades sociais, implicando a redefinição do papel do próprio Estado e das organizações da sociedade civil relativas à prestação de serviços sociais, entre eles a educação. As políticas sociais assumem, assim, novo sentido: constituem parte da estratégia de construção de uma nova hegemonia cujos princípios baseiam-se na lógica do livre mercado, na competitividade e na produtividade, tendo em vista a maximização do lucro. Objetivam amenizar os impactos negativos das políticas de ajuste estrutural - desemprego, pobreza e exclusão e da desigualdade social.

As políticas públicas destinadas à educação profissional inicial de jovens e adultos trabalhadores inserem-se neste contexto: o esvaziamento da escolarização de jovens e adultos por parte do Ministério da Educação; a descontinuidade das ações educacionais; a indefinição de responsabilidades entre as esferas de governo e a falta de efetivo compromisso com a modalidade do ponto de vista da alocação permanente de verbas públicas apontam para a secundarização destas políticas no interior das políticas educacionais. 
Em resposta às demandas por políticas para juventude recomendadas pelos organismos internacionais, principalmente pelo Banco Mundial, foi criado em 2004, o Grupo de Trabalho Interministerial, sob a coordenação da Secretaria Geral da Presidência da República, que implementou em 2005 a Política Nacional de Juventude, orientada para as questões educacionais e de inclusão, acompanhada de três ações: a constituição de uma Secretaria Nacional da Juventude, a implantação do Conselho Nacional de Juventude, e a implantação do Programa Nacional de Inclusão de Jovens (Projovem).

Em 2008, o Projovem é reformulado em distintas modalidades, entre elas o Programa Projovem Trabalhador, criado pela lei n. 11.692, de 10 de junho de 2008 e regulamentado pelo decreto n. 6.629, de 4 de novembro de 2008. O Projovem Trabalhador é a unificação dos programas Consórcio Social da Juventude, Juventude Cidadã e Escola de Fábrica. Visa à qualificação profissional, o desenvolvimento, humano e a inserção no mundo do trabalho e está sob a responsabilidade do MTE e da Secretaria Nacional de Juventude.

Em 2009, a Prefeitura do Rio de Janeiro - por meio da Secretaria Municipal de Trabalho e Emprego (SMTE) - assumiu, em parceria com o MTE, o Projovem Trabalhador na sua modalidade Juventude Cidadã, com o objetivo de preparar os jovens entre 18 e 29 anos, de famílias com renda per capita de até meio salário mínimo, para o mercado de trabalho e para buscar ocupações alternativas geradoras de renda. A meta era qualificar 7.000 jovens e inserir no mercado de trabalho no mínimo 30\%, considerando a contratação formal e as alternativas de ocupação, emprego e renda.

Os diversos cursos se distribuíram em 11 arcos ocupacionais, entre eles o arco ocupacional saúde, ministrados pela ONG Centro de Cidadania Cidade Maravilhosa (CCCM), que ofereceu em 2010 cursos em quatro ocupações: auxiliar administrativo em hospitais e clínicas; recepcionista de consultório médico e dentário; atendente de laboratório de análises clínicas; atendente de farmácia (balconista). Os cursos, com carga horária de 350 horas/aula em 24 semanas, estruturaram-se em duas partes: Núcleo Básico (qualificação social), 4 com carga horária de 100 horas/aula e o Núcleo Profissionalizante (qualificação profissional) com 250 horas/aula. O Núcleo Básico foi organizado com base nas competências e os conteúdos foram divididos em módulos, com ênfase na cidadania, baseada na compreensão dos direitos civis e sociais garantidos pelos instrumentos legais. Os temas relacionados ao mundo do trabalho estiveram ligados à formação do trabalhador empreendedor e autônomo, na perspectiva do mercado.

Identificou-se na pesquisa realizada que a ênfase na cidadania e no protagonismo dos jovens, por um lado, é parte da sua luta histórica. Por outro lado, é também recomendação do Banco Mundial, como apontou o Relatório sobre o Desenvolvimento Mundial de 2007 (Banco Mundial, 2007). Segundo esse documento, a cidadania ressalta a forma como os indivíduos devem 
reivindicar os seus direitos e responsabilizar as autoridades públicas por suas ações e, por isso, a importância do seu exercício pela juventude. $\mathrm{O}$ relatório considera que passando a fazer parte da comunidade, para além da família, a juventude pode exercer mais ativamente seus direitos e é esperado que assuma deveres. Seria, portanto, importante desenvolver a capacidade de 'participação cívica produtiva', atuando politicamente e em organizações sociais, pois "as frustrações dos jovens podem transformar-se em comportamento violento e levar à instabilidade econômica e social", prejudiciais aos investimentos privados (apud Deluiz, 2010, p. 20).

Entretanto, a cidadania que se constrói na e para uma conformação econômica e política de caráter neoliberal e para a reprodução do sistema de produção vigente não se configura de forma universal, inclusiva, especialmente para os jovens pobres e para a população das camadas socialmente excluídas, como os desempregados, analfabetos e trabalhadores rurais sem-terra e urbanos sem-teto, como apontou Alvarenga (2010).

No Núcleo Profissionalizante, além da divisão dos conteúdos em módulos, seus objetivos foram elaborados por competências, partindo das descrições da Classificação Brasileira de Ocupações (CBO) do MTE. Segundo Deluiz (2001b), o formato modularizado dos conteúdos é, em geral, perpassado por uma concepção oriunda do modelo de competências com enfoque nas matrizes condutivista e funcionalista, em que os conteúdos da análise ocupacional são transpostos linearmente para o currículo e os processos de aprendizagem ficam submetidos aos comportamentos e desempenhos observáveis na ação.

O MTE definiu, por meio do quadro referencial de conteúdos, que competências os alunos deveriam adquirir para executar as tarefas das respectivas ocupações, e o desenvolvimento destas competências ficava a critério das ONGs executoras.

\section{O olhar dos alunos do Projovem Trabalhador no Rio de Janeiro}

Considerou-se, do ponto de vista metodológico, que a compreensão de como os jovens pobres configuram seus espaços de experiência e dão sentido às suas expectativas torna-se relevante, pois possibilita situar estes indivíduos como sujeitos de sua história e não como simples objetos do mercado ou das políticas sociais. Desta forma, o modo como os jovens definem sua situação social, mais do que seus aspectos objetivos, tornou-se o foco da atenção analítica da presente investigação.

Os dados apresentados a seguir são resultantes de pesquisa qualitativa5 realizada com o universo dos alunos que frequentaram os cursos do arco ocupacional saúde em 2010, em um total de 58 alunos de quatro localidades 
do município do Rio de Janeiro - Ricardo de Albuquerque, Realengo, Campo Grande e Bento Ribeiro - onde foram ministrados cursos de qualificação profissional pela CCCM. Os jovens preencheram fichas de diagnóstico sobre sua situação econômica e foram realizados cinco grupos focais.

Com relação ao perfil dos alunos, dos 58 jovens entrevistados, a grande maioria era constituída por mulheres $(82,75 \%)$. Em pesquisa realizada sobre o Projovem Trabalhador em todas as regiões do Brasil, de 2008-2010, foram cadastrados 484.482 jovens, sendo maior a procura do programa por mulheres $(69,8 \%)$ em relação aos homens (30,2\%) (DIEESE, 2011). No Rio de Janeiro a razão foi de 38.428 mulheres $(71,1 \%)$ para 15.631 homens $(28,9 \%)$. No caso das mulheres, a probabilidade de estarem desempregadas ou inativas era três vezes maior em relação aos homens. Além desse dado há evidência de que a divisão sexual tradicional do trabalho tem peso importante na vida juvenil (Gonzalez, 2009). No Projovem Urbano de 2008 verificou-se, também, que dos 72 mil jovens matriculados nas primeiras turmas, 64,6\% eram do sexo feminino (Andrade et al., 2009). Estes dados reforçam a necessidade de efetivação de políticas públicas de inclusão que levem em consideração esse segmento, mais sujeito à discriminação e ao desemprego, como apontaram os autores.

Com relação à faixa etária, predominaram os jovens de 18 a 24 anos $(65,5 \%)$, o que os coloca na faixa dos 'jovens-jovens', segundo padrão internacional de conceituação de juventude (Brasil/MTE, 2011), enquanto na faixa entre 25 a 29 anos, denominados de 'jovens adultos', estão 34,5\% dos alunos. Estes dados são compatíveis com os apresentados no Anuário do DIEESE (2011) nos quais os jovens cadastrados no Projovem Trabalhador no período de 2008-2010 no país estavam, predominantemente, na faixa etária de 18 a 24 anos $(63,1 \%)$, enquanto a faixa de 25 a 29 anos abarcava $31,0 \%$ dos cadastrados no programa.

Do grupo analisado na pesquisa, $87,9 \%$ tinha o segundo grau completo, o que é compatível com as estatísticas referentes ao município do Rio de Janeiro de taxas altas de escolaridade entre os jovens, independentes do grupo social. Este dado é também compatível com a especificidade do arco ocupacional saúde no Projovem Trabalhador no município do Rio de Janeiro, que demandou prioritariamente este nível de escolaridade dos alunos. Outro fator que poderia ter influenciado na procura dos jovens mais escolarizados foi a divulgação do programa nas igrejas evangélicas da cidade, principalmente a igreja batista. ${ }^{6}$

A maioria dos alunos vivia com a família nuclear - pais/irmãos ou esposo/filhos - ou ampliada (avós e tios), e não era chefe de família. Do total de 58 alunos 69,0\% não contribuíam para a renda familiar e apenas 31,0\% contribuíam sempre ou eventualmente. A renda das famílias concentrava-se entre um e menos que dois salários mínimos $(67,24 \%)$, considerando-se que 
o salário mínimo referente a ocupações menos qualificadas no Estado de Rio de Janeiro em 2010, época da pesquisa, era de $\mathrm{R} \$ 581,88$.

À época dos cursos, 75,4\% dos jovens estavam desempregados e os $24,6 \%$ que estavam trabalhando o faziam em empregos precários, sem carteira, como autônomos ou biscateiros ('vende roupas', 'olha crianças na creche', manicure, construção civil, garçom, entre outras ocupações). Entre os que não estavam trabalhando, $31,6 \%$ se denominaram candidatos ao primeiro emprego, 24,5\% consideraram-se desempregados e 19,3\% estudantes. Constatou-se na investigação, tal como também observou Dayrell (2003) em seu estudo, a permanente busca por trabalho pelos jovens, o que indica a centralidade do trabalho em suas vidas

Nos últimos três anos, 65,5\% dos alunos fizeram cursos de qualificação profissional nas áreas de saúde, informática, administração, telemarketing e outras (beleza, petróleo e gás, entre outros). Estes dados confirmam que estes jovens trabalhadores de baixa renda, apesar de terem uma escolaridade de ensino médio completo, buscam constantemente uma qualificação para entrarem ou permanecerem no mercado de trabalho. Na ocasião em que no Programa Projovem Trabalhador, a maioria estava em casa 'sem fazer nada' (40,0\%), o que revela a falta de opção profissional destes jovens após a conclusão do ensino médio e dos inúmeros cursos de formação inicial e continuada realizados.

Com relação ao modo como os jovens ficaram sabendo do curso, $48 \%$ afirmaram ter tido conhecimento do curso por amigos. Em pesquisa sobre o Projovem Urbano em 2008, 25\% dos alunos do programa não empreenderam qualquer iniciativa para a obtenção de trabalho remunerado, e um dos motivos alegados foi a falta de redes de apoio, característica bem marcante desse grupo social. Em alguns casos são as redes de sociabilidade mais próximas (amigos, vizinhos e família) os meios disponíveis para esse fim, no caso, a família, com $28,8 \%$ das respostas, e os vizinhos e amigos, com $25,7 \%$ (Andrade et al., 2009).

Os dados obtidos na presente pesquisa assemelham-se aos encontrados em estudo de Andrade et al. (2009) sobre o Projovem Urbano, que ressalta que este conjunto de indicadores é compatível com os dados observados entre os alunos da Educação de Jovens e Adultos, os quais reproduzem as principais características das populações situadas nos estratos mais empobrecidos da sociedade brasileira. São sujeitos marcados por desigualdades e discriminações, dada a sua origem social, étnico-raciais, e disparidades econômicas, que se combinam e se potencializam, produzindo diferentes graus de vulnerabilidade.

No estudo de Corrochano et al. (2008) verificou-se que o trabalho é uma questão central para os jovens brasileiros e que a grande maioria deles encontra-se no mercado de trabalho, trabalhando ou em busca de um emprego. Embora o desemprego seja ainda o grande desafio para a juventude, os 
autores ressaltam que este não atinge da mesma forma os jovens. Há diferenças significativas quando considerados faixa etária, renda familiar, sexo, cor/raça e escolaridade. O desemprego não atinge apenas aqueles que têm baixa escolaridade. No caso das mulheres, inclusive, mesmo com escolaridade mais alta em relação aos homens, elas estão mais sujeitas ao desemprego, o que também foi verificado na pesquisa.

Ao avaliar as concepções e estratégias pedagógicas das ações de qualificação profissional, os alunos dos cursos apontaram que os conteúdos ministrados na área de saúde eram muito simplificados, sem a compreensão sobre uma concepção ampliada de saúde como direito de todos e dever do Estado, e dos princípios que regem o Sistema Único de Saúde (Lima, 2010). $\mathrm{E}$, ainda, que o material didático era insuficiente e ultrapassado e que não houve uma parte prática que pudesse consolidar o aprendizado 'teórico'. Entre os pontos positivos, os alunos mencionaram o desempenho dos professores, a dinâmica das aulas e as metodologias participativas utilizadas, a complementação dos conhecimentos em relação às apostilas superficiais e fracas e o relacionamento entre os alunos, o entrosamento, a superação da timidez, a sociabilidade. Outros pontos positivos mencionados pelos alunos relacionaram-se com os aspectos comportamentais e com a subjetividade - aprenderam noções de como se comportar no mercado de trabalho, se comunicar, ter mais iniciativa, lidar com as pessoas, ter autoestima -, e com o conhecimento dos direitos do trabalhador e do cidadão.

No que se refere às concepções de educação profissional em saúde e às estratégias pedagógicas destas derivadas, partimos do pressuposto que estão em disputa diferentes concepções, que refletem distintos projetos de sociedade e visões de mundo e que podem ser sintetizadas em duas lógicas: a (neo)pragmatista e a histórico-crítica. A primeira centra-se nas micronarrativas (Gonçalves, 2009), nas experiências e relações pessoais dos sujeitos, desconsiderando as relações de classe. Enfatiza as competências comportamentais em detrimento dos conhecimentos formais dos trabalhadores, valorizando os métodos em relação aos conteúdos disciplinares (Ramos, 2010). Na lógica neo-pragmatista são relevantes os conhecimentos, habilidades e competências que assumem uma utilidade prática e imediata e garantam a empregabilidade dos trabalhadores (Deluiz, 2001b).

A segunda propõe uma formação politécnica e omnilateral, na tradição marxista (Manacorda,1991), compreendendo a unidade teoria-prática; o trabalho como princípio educativo, e considerando o desenvolvimento da totalidade das potencialidades dos sujeitos, referindo-se a uma formação humana oposta à formação unilateral provocada pelo trabalho alienado e pela divisão social do trabalho.

A percepção dos alunos sobre as concepções e estratégias pedagógicas do curso mostra a predominância de uma concepção pedagógica de educação 
profissional em saúde instrumental, ancorada no (neo)pragmatismo, a qual adota o critério de utilidade dos conhecimentos para o mercado enfatizando as competências comportamentais, que não considera a unidade teoria-prática, que privilegia as metodologias e as atividades escolares em detrimento da construção de conteúdos relevantesque são simplificados e/ou desconsiderados. Essa estratégia discute as questões centrais para os jovens - de gênero, étnicas, culturais e do trabalho - a partir das suas realidades na forma de micronarrativas, sem uma perspectiva coletiva, de classe.

Com relação às mudanças na dimensão educacional (formação profissional e continuidade dos estudos), na econômica (geração de trabalho e renda), na psicossocial (subjetividade, autoestima, melhor comunicação e sociabilidade) e na político-social (exercício da cidadania), os alunos consideraram que houve uma grande expectativa de se qualificar, ampliar conhecimentos sobre a área da saúde, ter chances no mercado de trabalho, receber o certificado para acrescentar ao currículo e ter mais oportunidades e mais experiência, como estratégias de vida. Entretanto, a qualidade da formação foi deficiente, a maioria dos alunos continuou desempregada e a participação na comunidade resumiu-se às atividades na igreja, da qual já participavam.

Na percepção dos alunos, o maior ganho foi na compreensão de seus direitos, na medida em que passaram a reivindicar o pagamento atrasado das bolsas e das passagens a ONGs e à SMTE, tornando-se protagonistas nas relações com estas instituições. Como perspectivas de futuro, pretendem dar continuidade aos estudos e realizar outros cursos de qualificação profissional, como forma de obter mais chances no mercado de trabalho. Tais resultados confirmam os dados do estudo de Andrade et al. (2009), que ressaltam que se o interesse inicial do aluno é a qualificação para o trabalho, uma vez inserido no programa, a maior contribuição que este lhe oferece é a possibilidade de continuar os estudos. Os autores relacionam estes achados a dois motivos: à não satisfação de suas expectativas no sentido de formar-se para o trabalho e à atuação dos docentes que, muitas vezes, agem como incentivadores da retomada da vida escolar de seus alunos.

Considerando os resultados obtidos, é possível concluir que permanecem os mesmos impasses constatados em pesquisas com relação aos programas de qualificação anteriores (Deluiz, 2003; 2006; 2009): falta de articulação das ações de formação profissional com as da educação básica; a falta de um itinerário formativo; desenho de cursos de forma fragmentada, com carga horária mínima, tendo em vista as necessidades da formação; uma perspectiva de educação profissional orientada por uma racionalidade instrumental, que considera o processo formativo em uma dimensão restrita, operacional e a parceria/subcontratação entre ONGs que dificultam o acompanhamento, o controle social e a responsabilização das ONGs por suas ações formativas. 
Em seu estudo sobre jovens e trabalho e os desafios para as políticas públicas no Brasil, Corrochano et al. (2008) apontam que as afinidades de problemas constatados nas formas de implementação de vários programas, explicam-se em geral, pela histórica precariedade que caracterizam as ações no país ao longo dos tempos. As iniciativas dirigidas às juventudes reproduzem inúmeros problemas da área social: a escassez de recursos, o desenvolvimento de programas focalizados em detrimento de propostas estruturais, a pouca articulação entre os vários setores da gestão pública, entre outros. Segundo os autores, há necessidade de ações que envolvam a qualificação e a facilitação do acesso às vagas ofertadas pelo mercado, mas que também atentem para a realidade vivida pelos jovens nos espaços de trabalho. Ressaltam que não basta apenas proferir que a juventude é diversa, múltipla e que são várias as juventudes. Essa diversidade tem resultado em uma enorme desigualdade, e nesse sentido, as ações que desconsiderem a diversidade podem manter ou até mesmo multiplicar o atual quadro de desigualdades entre os jovens do país.

\section{Considerações finais}

Quanto à dimensão educacional (qualificação profissional e ampliação da escolaridade), as ações implementadas no Projovem Trabalhador na área da saúde adotam uma racionalidade instrumental, pragmática, considerando o processo formativo em uma dimensão restrita e simplificadora da formação.

Não é desenvolvida uma formação profissional integral, omnilateral, comprometida com o desenvolvimento de todas as potencialidades humanas, articulando trabalho, ciência e cultura, e que considera a totalidade das dimensões que constituem a vida do trabalhador. Tampouco é abordada uma perspectiva da saúde como um conceito multifacetado, com diferentes dimensões que se articulam e se influenciam mutuamente. Desconsiderou-se, no curso, a natureza contraditória do trabalho em saúde sob o capitalismo, que apresenta caráter de mercadoria e, ao mesmo tempo, garante a produção da existência humana, daí sua dimensão humanizadora e emancipatória. Finalmente, não se compreendeu o processo de trabalho em saúde como complexo, heterogêneo e fragmentado, impactado pelas novas tecnologias e formas de gestão do trabalho (Deluiz, 2001a) e o trabalhador em saúde como parte da classe trabalhadora e que enfrenta o desafio do desemprego e da precarização e apresenta diferentes níveis de qualificação, gerando demandas para a educação profissional. Apesar da precariedade das ações de formação oferecidas, a maioria dos alunos continua fazendo cursos de qualificação profissional e muitos mencionam a necessidade de ter que continuar os estudos para além do ensino médio, como forma de obter maiores chances no mercado de trabalho. 
Quanto à dimensão econômica (trabalho/renda), os alunos não se sentem preparados para enfrentar o mundo do trabalho, mas continuam a buscar a inserção no mercado. O trabalho permanece central em suas vidas, não somente devido à necessidade de sobrevivência, mas como fator de identidade profissional e social.

No que se refere à dimensão psicossocial, constatou-se a referência às questões relativas à subjetividade, tais como a melhoria da autoestima, a iniciativa e o melhor relacionamento com as pessoas.

Quanto à dimensão político-social, os resultados apontaram que os alunos, apesar de participarem ativamente nas suas igrejas, deixam de atuar em outros organismos da sociedade civil (sindicatos, associações, entre outros), ou outros espaços que possibilitassem o exercício efetivo da cidadania.

As políticas de qualificação profissional voltadas para os extremamente pobres objetivam o alívio da pobreza e o enfrentamento das tensões sociais, com ações educativas que assumem um caráter superficial e fragmentado. $\mathrm{E}$ por não viabilizarem a formação profissional autônoma e emancipatória, acabam legitimando a exclusão do conhecimento e do trabalho dos contingentes mais vulneráveis da população. Reafirmam-se, assim, as características de focalização das políticas, de descentralização e de participação do setor privado no campo educacional, por meio da parceria público-privado, na qual as ONGs jogam um papel relevante, em detrimento da ação de controle público e de avaliação do Estado.

Apesar da criação de uma Política Nacional de Juventude e da tentativa de articulação entre os diversos programas e ações, as políticas de educação profissional inicial e continuada voltada para os jovens, desenvolvidas nos últimos anos, ainda permanecem distantes da lógica das políticas de integração, de caráter universal. Convertem-se em políticas de inserção (Castel, 1998), compensatórias, assistencialistas e emergenciais, chegando aos territórios previamente formatadas e fragmentadas, sem articulação com as demais políticas de trabalho e geração de renda e de desenvolvimento local.

Em um contexto de despolitização da economia, de desregulação do mercado financeiro e do trabalho e novas relações entre Estado e sociedade civil, as políticas sociais pretendem responder à crescente desigualdade econômica, social e política que atinge os segmentos excluídos dos direitos básicos de cidadania. Entretanto, ao se reduzirem a ações compensatórias e emergenciais, desarticuladas das políticas de educação, trabalho/renda e desenvolvimento, e sem enfrentarem questões de fundo, como a acumulação do capital e a socialização da riqueza, tendem a perpetuar o ciclo da desigualdade e da exclusão social.

Contudo, as políticas não são mero reflexo das normas e orientações ditadas pelos organismos internacionais ou resultantes de opções e decisões políticas que relegam a um plano secundário os interesses dos jovens das 
classes trabalhadoras. Elas adquirem materialidade na sua ação prática e deixam entrever as contradições e os conflitos da própria realidade social. As percepções dos alunos e os sentidos que atribuem ao Programa Projovem Trabalhador, detectados na investigação, refletem estas contradições, de que os jovens não são somente receptores passivos de políticas fragmentadas a eles destinadas, mas convertem-se em sujeitos de direitos, em protagonistas que reivindicam uma formação que atenda aos seus interesses e que viabilize a construção de outro tipo de inserção das camadas empobrecidas na constituição de uma sociedade mais justa e igualitária.

\section{Notas}

1 Pesquisadora visitante, pelo Conselho Nacional de Desenvolvimento Científico e Tecnológico (CNPq), no Programa de Pós-graduação em Educação Profissional em Saúde da Escola Politécnica de Saúde Joaquim Venâncio, da Fundação Oswaldo Cruz (EPSJV/Fiocruz), Rio de Janeiro, RJ, Brasil. Doutora em Educação pela Universidade Federal do Rio de Janeiro (UFRJ).<ndeluiz@uol.com.br>

Correspondência: Programa de Pós-graduação em Educação Profissional em Saúde, Escola Politécnica de Saúde Joaquim Venâncio, Fundação Oswaldo Cruz, Avenida Brasil, 4.365, CEP 21040-900, Manguinhos, Rio de Janeiro, RJ, Brasil.

2 Pesquisadora Assistente da Estação de Trabalho Observatório de Técnicos em Saúde, da Rede Observatório de Recursos Humanos em Saúde do Brasil sediado na Escola Politécnica em Saúde Joaquim Venâncio, da Fundação Oswaldo Cruz (EPSJV/Fiocruz). Mestre em Educação Profissional em Saúde pela Escola Politécnica de Saúde Joaquim Venâncio, da Fundação Oswaldo Cruz (EPSJV/Fiocruz).<biaveloso@fiocruz.br>

3 Arcos ocupacionais são agrupamentos de ocupações relacionadas, que possuem base técnica próxima e características complementares. Cada um dos arcos pode abranger as esferas da produção e da circulação (indústria, comércio, prestação de serviços), garantindo assim uma formação mais ampla, de forma a aumentar as possibilidades de inserção ocupacional do/a jovem trabalhador/a, seja como assalariado, autoemprego ou economia solidária. Embora um arco possa apresentar um número maior de ocupações, a presente proposta trabalha com no mínimo quatro e no máximo cinco ocupações por arco, limitação determinada a partir da carga horária disponível (Brasil, 2007).

4 A qualificação social compreende: inclusão social (40hs/aula); valores humanos, ética e cidadania (10hs/aula); educação ambiental, higiene pessoal, promoção da qualidade de vida (10hs/aula), noções de direitos trabalhistas, formação de cooperativas, prevenção de acidentes de trabalho (20hs/aula) e estímulo e apoio à elevação da escolaridade (20hs/aula).

5 A pesquisa “Juventude, Trabalho, Saúde e Educação Profissional: o Projovem Trabalhador no Rio de Janeiro", contou com o financiamento do CNPq e foi realizada no período de 2010-2012, com a aprovação do Comitê de Ética, sob a coordenação da profa. Neise Deluiz, 
em conjunto com as mestrandas Bianca Veloso e Mércia Maria dos Santos, no Programa de Pós-graduação em Educação Profissional em Saúde da Escola Politécnica de Saúde Joaquim Venâncio (EPSJV) da Fundação Oswaldo Cruz (Fiocruz).

6 Não foi possível saber que acordos a Secretaria Municipal do Trabalho e Emprego da Prefeitura do Rio de Janeiro fez com os líderes das igrejas batistas para que essa divulgação fosse feita deste modo. $\mathrm{O}$ fato é que a maioria dos alunos pertencia a estas igrejas.

\section{Referências}

ABRAMO, Helena W. O uso das noções de adolescência e juventude no contexto brasileiro. In: FREITAS, Maria V. (Org.). Juventude e adolescência no Brasil: referências conceituais. São Paulo: Ação Educativa, 2005. Disponível em: <www.bibliotecaacaoeducativa.org.br/dspace/bitstream/ 123456789/2344/1/caderno_Juv.pdf > . Acesso em: 10 nov. 2011.

ALVARENGA, Márcia S. Sentidos da cidadania: políticas de educação de jovens e adultos. Rio de Janeiro: EdUERJ, 2010.

ANDRADE, Eliane Ribeiro et al. Composição social e percursos escolares dos sujeitos do Projovem: novos/velhos desafios para o campo da educação de jovens e adultos. Em Aberto, Brasília, v. 22, n. 82, p. 73-89, nov. 2009.

ANTUNES, Ricardo. Adeus ao trabalho?: ensaio sobre as metamorfoses e centralidade do mundo do trabalho. São Paulo: Cortez; Campinas, SP: Ed. da UNICAMP, 2005.

BANCO MUNDIAL. Relatório sobre o Desenvolvimento Mundial de 2007: o desenvolvimento e a próxima geração: visão geral. Banco Mundial: Washington, DC, 31 p. Disponível em: <www.wds.worldbank.org/ external/default/WDSContentServer/WDSP/ IB/2008/08/11/000333037_20080811011756/ Rendered/PDF/449630WDROPORT 1070 overview01PUBLIC1.pdf $>$. Acesso em: 8 mar. 2012.
BRASIL. Portaria n. 615, de 13 de dezembro de 2007. Arco de ocupações para jovens. Anexo I. 2007. Disponível em: <http://portal.mte. gov.br/data/files/FF8080812BD96D6A012BE 39D057842BF/p_20071213_615_anexos.pdf>. Acesso em: 15 fev. 2011

. Ministério do Trabalho e Emprego. Agenda nacional de trabalho decente para a juventude. Brasília: MTE, SE, 2011. Disponível em: <www.oitbrasil.org.br/sites/ default/files/topic/decent_work/doc/antdj_ mte_535.pdf >. Acesso em: 11 fev. 2011.

CASTEL, Robert. As metamorfoses da questão social: uma crônica do salário. RJ: Vozes, 1998.

CATTANI, Antonio David. Desigualdades socioeconômicas: conceitos e problemas de pesquisa. Sociologias. Porto Alegre, ano 9, n.18, p.74-99, jul./dez. 2007.

CORROCHANO, Maria Carla et al. Jovens e trabalho no Brasil: desigualdades e desafios para as políticas Públicas. São Paulo: Ação Educativa, 2008.

DAYRELL, Juarez. O jovem como sujeito social. Revista Brasileira de Educação, Rio de Janeiro, n. 24 , p. 40-52, set./ out./ nov./ dez, 2003.

DELUIZ, Neise. Qualificação, competências e certificação: visão do mundo do trabalho. Revista Formação do MS, Brasília, n. 2, maio, 
2001 a. Disponível em: <http://bvsms.saude. gov.br/bvs/publicacoes/profae/Revista2002. pdf > . Acesso em: 15 fev. 2012.

O modelo das competências profissionais no mundo do trabalho e na educação: implicações para o currículo. Boletim técnico do Senac, Rio de Janeiro, v. 27, n. 3, p.12-25, set./dez., 2001 b.

. As organizações da sociedade civil e suas propostas e práticas de educação profissional. Relatório final. Rio de Janeiro: CNPq, 2006.

Sociedade civil e as políticas de educação de jovens e adultos: a atuação das ONGs no Rio de Janeiro. Relatório final. Rio de Janeiro: CNPq, 2009.

Projovem trabalhador: Avanço ou continuidade nas políticas de Qualificação Profissional. Boletim Técnico do Senac, Rio de Janeiro, v. 36, n. 2, 2010. Disponível em: <www.senac.br/BTS/362/artigo2.pdf >. Acesso em: 16 jan. 2012.

DELUIZ, Neise; GONZALEZ, Wânia; PINHEIRO, Beatriz. ONGs e Políticas Públicas de Educação Profissional: propostas para a educação dos trabalhadores. Boletim Técnico do Senac, v. 29, n. 2, maio/ago. 2003.

DIEESE (Departamento Intersindical de Estatística e Estudos Socioeconômicos). Anuário do Sistema Público de Emprego, Trabalho e Renda 2010/2011: juventude. 3. ed. São Paulo: DIEESE, 2011.

FRIGOTTO, Gaudêncio. Juventude, trabalho e educação no Brasil: perplexidades, desafios e perspectivas. In: NOVAES, Regina; VANNUCHI, Paulo. (Org.). Juventude e sociedade: trabalho, educação, cultura e participação. São Paulo: Fundação Perseu Abramo, 2004, p. 180-216.

GONÇALVES, Etinete. Educação e neopragmatismo. 2009. 273 p. Tese (Doutorado em Políticas Públicas e Formação Humana) - Rio de Janeiro: UERJ, 2009.
GONZALEZ, Roberto. Políticas de emprego para jovens: Entrar no mercado de trabalho é a saída? In: CASTRO, Jorge Abrahão; AQUINO, Luseni M. C. de; ANDRADE, Carla C. (Org.). Juventude e politicas sociais no Brasil. Brasília: Ipea, 2009, p.109-128.

GROPPO, Luís A. Juventude: ensaios sobre sociologia e história das juventudes modernas. Rio de Janeiro: DIFEL, 2000.

HARVEY, David. Condição pós-moderna. São Paulo: Loyola, 1992.

HOBSBAWM, Eric. Era dos extremos: o breve século XX: 1914-1991. São Paulo: Cia. das Letras, 1995.

LIMA, Júlio C. F. Política de saúde e formação profissional dos trabalhadores técnicos de enfermagem. Tese (Doutorado Políticas Públicas e Formação Humana). Rio de Janeiro: Políticas, UERJ, 2010.

MANACORDA, Mário. Marx e a pedagogia moderna. São Paulo: Cortez, 1991.

MONTAÑO, Carlos. Terceiro setor e questão social: crítica ao padrão emergente de intervenção social. São Paulo: Cortez, 2002.

POCHMANN, Márcio. A batalha pelo primeiro emprego: as perspectivas e a situação atual do jovem no mercado de trabalho brasileiro. São Paulo: Publisher Brasil, 2000.

RAMOS, Marise. Trabalho, educação e corren-tes pedagógicas no Brasil: um estudo a partir da formação dos trabalhadores técnicos da saúde. Rio de Janeiro: EPSJV; UFRJ, 2010.

SALAMA, Pierre; VALIER, Jacques. Pobrezas e desigualdades no terceiro mundo. São Paulo: Nobel, 1997.

SILVA, Maria O. da S. Pobreza, desigualdade e políticas públicas: caracterizando e problematizando a realidade brasileira. Revista Katálysis, UFSC, Florianópolis, v.13, n. 2, 2010. 
WANDERLEY, Luiz E. O enigma do social. In: CASTEL, Robert; WANDERLEY, Luiz E.; BELFIORE-WANDERLEY, Mariangela. Desigualdade e a questão social, 2. ed., São Paulo: Educ, 2004, p. 163-264.

Recebido em 13/06/2012

Aprovado em 12/11/2012 